\title{
EXPERIMENTAL ANALYSIS OF TRADITIONAL AND NFRP CONCRETE FOR FRAME MEMBERS
}

\author{
A. Anbuchezian \\ Principal \& Professor, Department of Civil Engineering, \\ AnnaPoorana Engineering College, Salem, Tamil Nadu, India \\ N. Chandrasekaran \\ Assistant Professor, Department of Civil Engineering, \\ Aishwarya College of Engineering and Technology, Tamil Nadu, India

\section{Vairavel} \\ Research and Development Head, \\ Tejatech and Design Solutions, Erode, Tamil Nadu, India
}

\begin{abstract}
The reinforced concrete is mixed with substances of natural fibrous that are termed as Natural Fiber-Reinforced Concrete and includes the cement-based grid that has been done out of cement, sand, water and additives, where small length filaments are dispersed. The primary purpose of this research is to promote an understanding of the joint efficiency, relating to Efficiency-Based Seismic Design (PBSD) of reinforced-concrete frameworks, to forecast the best results of earlier experimental studies of joints and to develop tools to assist PBSD of the separate joints. The improvement in the efficiency of seismic in relation to horizontal forces and operability leads to more powerful Beam-column joints. A lot of the analytic models and modeling have suggested to examine the various strengthening methods by using sheets of Nano Fiber Reinforced Polymer. In this study, one-point load test (PLT) was performed with real-time test benches to analysis the efficiency of beamcolumn joints reinforced with high-efficiency Nano fiber reinforced concrete in frame sample..
\end{abstract}

Keywords: Frame sample, Single PLT, NFRP mesh, Malleability, Energy-absorption

Cite this Article: A. Anbuchezian, N. Chandrasekaran, M. Vairavel, Experimental Analysis of Traditional and NFRP Concrete for Frame Members, International Journal of Advanced Research in Engineering and Technology (IJARET), 10 (6), 2019, pp 130-139.

http://iaeme.com/Home/issue/IJARET?Volume $=10 \&$ Issue $=6$

\section{INTRODUCTION}

Concrete is the most significant substance to construct various buildings and facilities since it can be fitted to any mold during the latter's green stage. Although it is being used as a well- 
identified construction substance globally. It retains low UTS, low ductility, and instability of volume, low UTS-to-mass ratio and insignificant resilience to fracture. The performance of concrete was improved to stress the failure of structure.

A seismic modernization is a variation in current structures to become more resistant to seismic activity, seismic motion or soil failure because of earthquakes. The structural elements of important components like beams, columns, beam-column joints are reinforced and designed to increase imprisonment of concrete. The techniques of retrofitting also apply for other natural disasters like hurricanes and heavy wind by lightning storms. Aim of retrofitting is to improve structure from the perspective of its intensity, ductility, reliability and accuracy of the existing building so that the efficiency of the building can be raised to the level to withstand the design earthquake.

Restoration is a structural measure that employs in order to enhance a building and to enhance seismic resistance prior to the occurrence of an earthquake. Retrofitting is structural measure that is performed to a building after an earthquake in order to strengthen. The performance of Reinforced Concrete (RC) moment that resists frame constructions in recent earthquakes globally underlined the result of a weak efficiency of beam-column joints.

During the seismic activity, the seismic-resistant construction is to make structures to fare better in comparison to their traditional counterparts. In recent times, new technology has surfaced which uses sheets of Fibre Reinforced Polymer to reinforce the structural components of the structures and constructions at a very quick rate due to the easy construction and the prospect of application without disturbing the existing functionality of the structure. FRP confinement retains more load-bearing capacity, enhanced plasticity and high-energy absorbing. The structures in the earthquake-prone regions rely on their inherent ductility to seismic excitations, which make them vulnerable to damage and collapse in the event of earthquake. The seismic load was neutralized by FRP that incorporates structural elements.

The diagonal metallic system had been introduced to protect the joint panel region from damage. Test results showed the efficiency in order to update the non-seismically intended $\mathrm{RC}$ frames and also strengthened the adaptability of the suggested design proceedings [1]. The experimental performance of concrete beams reinforced with a steel bar to discuss failure in the load, the regime of failure, deflection, and strain performance. The study reveals that proposed techniques most cost-effective reinforcement to increase the bending efficiency of $\mathrm{RC}$ beams [2].The loading has been implemented through a motion management regime. The four samples are utilized for experimentation. Based upon findings of experimental it is determined that, the second sample having extra reinforced beam and the oblique collar stirrups at joints is showing a better efficiency in comparison to the others three samples [3].An innovative technique for retrofitting BCJ was implemented by UHP-HFRC and enhances the efficiency of damaged BCJ. The maximum post efficiency was affected by the initial level of damage of BCJ [4].A new model of BCJ combines a new formula for joint power and the newly established factors for cyclic response. Based on models of frame joints and seismic motions, the analysis of dynamic has been carried out. The fragility curves are established through numerical study [5].The retrofit of RC BCJ using the fully clasped sloping element suggested as an optimization of an existing retrofit technique. After some initial numerical factors, experimental tests and digital simulations were performed in order to design reliable and cost-effective planning model. As a result, it was observed that stretching and the shearing rigidity of fixations are needed to assess their loading and the efficiency of the retrofit solution [6].A methodology has been suggested to summarize aftershocks based upon the information of the main shocks. Findings also indicate that the main shock is considered to underestimate the seismic risk [7].The findings of an experimental study are 
presented to improve shearing ability and ductility of RC beams by using strips of CFRP. When the samples strip of CFRP with and without port were compared, the peak strains at strips of port were about $56 \%$ greater in comparison to without port [8].

The factors have been numerically examined to study the impact of using wraps of FRP around the beam on the plasticity of the external BCJ. Results indicate that using wraps of CFRP around beam transforms the fragile failure to elastic failure [9]. The analysis of dynamic fracture has been utilized to simulate crack that spread within the concrete substance and anticipate dynamic detachment in CFRP consolidated with the approach of fracture mechanisms. It is determined that the breadth of strut area in the joint rises by using reinforced FRP [10].

\section{CHALLENGES FOR BEAM-COLUMN JOINT}

The beam-column joint must be stronger than neighboring hinging members because of sufficient size of joint or beam-column which has been modified to fulfill its power or requirements of port. So, a major flexural or stirrups in order to secure the full power of rebar are mobilized. The following shows the planning proceedings of beam-column joints.

- Selection of lengthwise bar on the basis of the magnitude of members and requirements of port.

- Ensure the appropriate bending strength of columns.

- Assessment of design shearing strength for the joint that retains a balance among the bending over the strength of the neighboring beams and its inner strength in the columns.

- Ensure that the shearing stress is less than the permitted stress limit.

- Offer crosswise reinforcements for shearing strength.

- Acquire an active joint shearing area from the adjacent member sizes.

- Offer enough port for consolidating passes and dissolution in the joint.

\section{FRAME SECTION}

Generally, high power applied by earthquake damage the resisting capacity of joints due to used substances has a limited impact carrying magnitude and intensity. Failure has to be avoided by using various procedures, but the repairing of joints that are damaged is extremely difficult. The internal forces induced by reformulation members are resisted by rigidity and intensity produced by joints.

The ultimate strength of frame joints should be created and maintained because this element with finite size will be always serious within the earthquake load. Due to the earthquakes, the performance of reinforced concrete moment resisting frame structures is highlighted by the consequences of poor efficiency of beam-column joints. From the analysis, the joints usually are considered to be as rigid. The honeycombing in concrete is carried out to avoid the overload of reinforced casting. It has a key role in structure of the buildings. It has to be built to withstand the effects of earthquake.

\section{PROBLEM STATEMENT}

The establishment of frame-section with efficiency and force of various ambiguities are being reviewed. The performance of frame joints with Nano fibers has been tested numerically and experimentally by cyclic loading. The samples are treated in the lab for 28 days to attain more strength with and without GFRC frame joint. Failures of casing joints are a weak port of lengthwise pillar bars, weak sectors and in adequate cross-sector support. The external joint 
frame and corner joints show the options of variations in performance. NFRP-reinforced predamaged concrete frame joints are power full in comparison to traditional frame joints.

\section{MATERIAL AND METHODS}

Figure 1 demonstrates the methodology of this research. In this research, the utilized materials are cement, coarse and fine aggregate, fuel ash, M-sand, super plasticizer, water, NFRP mesh and high-capacity intensity deformed bars as reinforcement are discussed below.

\subsection{Araldite aw 106 \& Hardener HV 953 u Descriptions}

Re Araldite ${ }^{\circledR}$ AW 106/Hardener HV 953 U is a versatile, two-portion, room temperature hardening, adhesive glue of a high-quality and resilience that holds a wide variety of metals, pottery, Fiber, elastic, rigid plastics and so on. It is a customizable cement for specialists and most industrial uses. Figure 2. Displays the Araldite hardener and Table 1defines the characteristics of the hardener.

Table 1. Description of Aralditre aw 106 \& Hardener HV 953

\begin{tabular}{|c|c|c|c|}
\hline Characteristics & Araldite ${ }^{\circledR}$ AW106 & Hardener HV 953 U & Mix \\
\hline Colour (visual) & Neutral & Pale yellow & Pale yellow \\
\hline Specific gravity & Ca. 1.15 & Ca. 0.95 & Ca. 1.05 \\
\hline Viscosity at $25^{\circ} \mathrm{C}$ & $30-50(\mathrm{Pas})$ & $20-35(\mathrm{Pas})$ & $30-45(\mathrm{Pas})$ \\
\hline Pot Life $\left(100\right.$ gm at $25^{\circ} \mathrm{C}$ & - & - & Ca. 100 minutes \\
\hline Shelf life $\left(2-40^{\circ} \mathrm{C}\right)$ & 3 years & 3 years & - \\
\hline
\end{tabular}

\section{NANO FIBER (NFRP)}

Fibers are the vital ingredients in a fiber-reinforced composite material. NFRP reinforcing bars were utilized as main strengthening for concrete structures. Nano fiber is further termed as fibre Nano. It is a material that is generated using for extraordinarily fine fibre of Nano due to its lightweight, robust, energetic, and inexpensive in comparison to metals. These fibers have less feasibility, good quality and characteristics of mass and it can easily be formulated by the use of shaping techniques. Table 2.Lists the features of the Nano fiber mesh.

Table 2. Properties of Nano fiber mesh

\begin{tabular}{|c|c|c|}
\hline S.No & Characteristic of Nano fiber mesh & Values \\
\hline 1 & Tensile strength $(\mathrm{MPa})$ & 3380 \\
\hline 2 & Compressive Strength $(\mathrm{MPa})$ & 1098 \\
\hline 3 & Density $\left(\mathrm{g} / \mathrm{cm}^{3}\right)$ & 2.52 \\
\hline 4 & Heat expansion $\left(\mu \mathrm{m} / \mathrm{m} .{ }^{\circ} \mathrm{C}\right)$ & 4.58 \\
\hline 5 & Softening $\mathrm{T}\left({ }^{\circ} \mathrm{C}\right)$ & 848 \\
\hline 6 & Poisson`s ratio & 0.2 \\
\hline
\end{tabular}

Table 3. Mix Percentage of cement for reinforcement

\begin{tabular}{|c|c|c|c|c|c|}
\hline $\begin{array}{l}\text { Cement } \\
(\mathbf{k g}) / \mathbf{m}^{3}\end{array}$ & $\begin{array}{c}\text { Fuel Ash } \\
(\mathbf{k g}) / \mathbf{m}^{3}\end{array}$ & FA $(\mathbf{k g}) / \mathbf{m}^{3}$ & $\mathrm{CA}(\mathrm{kg}) / \mathrm{m}^{3}$ & Water $(\mathrm{kg}) / \mathbf{m}^{3}$ & $\begin{array}{c}\text { Super Plasticizer } \\
(\mathrm{kg}) / \mathbf{m}^{3}\end{array}$ \\
\hline 285 & 122 & 724 & 1180 & 148 & 8.14 \\
\hline \multicolumn{2}{|c|}{1} & 1.78 & 2.90 & 0.364 & 0.055 \\
\hline
\end{tabular}

\section{DIMENSIONS OF SAMPLE}

In this research, the grade of M40is the utilized grade of concrete and the grade of Fe500 is the utilized steel. The final mixture of concrete .The intensity and performance of frame joints 
that are using composites with single point load testing are being reviewed. The frame joints reach the peak curving moment, shearing strength and also frame joints are vulnerable in nature. So, frame joint is a failure at bond and shear collapse mechanism. Hence, this work examines the variations in the intensity, rigidity, ductility and the ability of energy dissipation in frame joints by composites of concrete with NFRP mesh 1 length x 0.150 width in all dimension Meter.

\section{REINFORCEMENT DETAILS}

The main strengthening provided within the frame was $10 \mathrm{~mm}$ thick bars, 2 No's above and 2 No's undersides. The stirrups are $6 \mathrm{~mm}$ thick bars at $100 \mathrm{~mm} \mathrm{c} / \mathrm{c}$ for a distance. Lengthwise strengthening provided in the column was 4 No's of $10 \mathrm{~mm}$ thick bars are distributed evenly across the four sides of the column. The column restrictions are $6 \mathrm{~mm}$ thick bars at $100 \mathrm{~mm}$ $\mathrm{c} / \mathrm{c}$ for a distance of $100 \mathrm{~mm}$ from the face of the column. The NFRP mesh is positioned at intersections of the frame joint. Figure $5(\mathrm{a} \& \mathrm{~b})$. Demonstrates the placing of NFRP mesh inside the mold and modeling of frame sample.

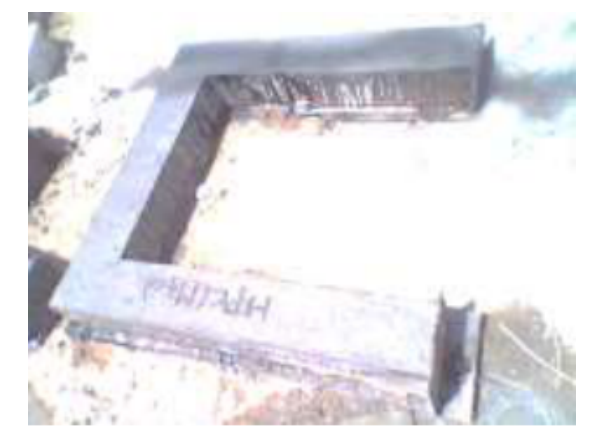

Figure 1 The casting of frame sample

Figure 6. Demonstrates the recommended frame samples after testing in the loading frame. Full-frame samples are being loaded up to the final load.

\section{SINGLE POINT LOAD TEST SETUP ON FRAME}

Single point demonstrates the test arrangement for single point load on a frame mounted on loading frame. The load is applied in the middle of the frame for the single point load frame. For both situations, screw jack has been employed to apply back and forth cyclic load. At each and every cycle, there is an increment in the level of load. So that the frame has been progressively loaded. The frame has been loaded until it gets failure and the values of load had been noted at the phases of initial fracture and final failure. Test results area trained from measurements of single-point load are discussed. In this area, it is demonstrated that loworder statistical data come crashing down well by using a single frame size thickness as a selfsimilar parameter. Finally, numerical and experimental findings are discussed below.

\section{EXPERIMENTAL TEST RESULTS ON TRADITIONAL CONCRETE FRAME WITH SINGLE POINT LOAD}

Demonstrates the cyclic load against the measurement of deflection in single point load testing for a frame without NFRP mesh. During each and every cycle, the level of load was increased from $3 \mathrm{kN}, 6 \mathrm{kN}, 9 \mathrm{kN}$, and so on up to failure load to load the frame progressively. During the initial cyclic load, the $1.2 \mathrm{~mm}$ of deflection was measured at center with $15 \mathrm{kN}$. When the level of load was increased in each cycle, the observed deflection was higher in comparison to the previous cycle. The $3.9 \mathrm{~mm}$ of peak deflection was measured at $32 \mathrm{kN}$ of the load. 
Ductility may be widely defined as the possibility of a structure which is to be subjected to rigid distortions beyond the initial yield deformity without a reduction in load resistivity. A bipolar load distortion response is referred by the quantifiable measure of ductility. The bipolar performance of beams had been assumed to determine the initial yield deflection. The ductility of displacement was measured by the ratio among the peak distortion of a specific cycle and the yield deflection.

Figure 2.demonstrates the cyclic load against aggregate ductility factor with single point load testing for a frame without NFRP mesh. During each and every cycle, the ductility was attained at peak level of load. These are summed up at each and every level. The summation of attained value defines the aggregate ductility up to any load point when the structure undergoes cyclic loading. Table 4 lists the values of ductility and aggregate ductility. The aggregate ductility has been found to improve from 0.53 during the initial cyclic load to 3.73 during the third cyclic load.

The process to compute the rigidity was as follows:

1. The tangent line has been established for each cycle of the hysteric curves at a load of

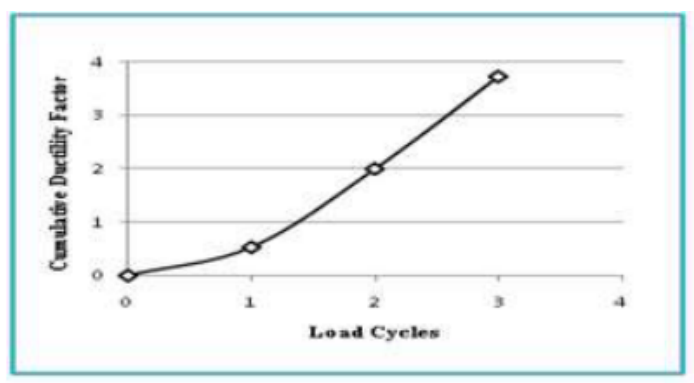

Figure 2. Cyclic load vs. Aggregate Ductility Factor $\mathrm{P}=0.75 \mathrm{P}_{\mathrm{u}(1)}$

Where $\mathrm{P}_{\mathrm{u}}$ - peak load of that cycle

2. Describe the angle of tangential drawn to each cycle that gives the rigidity of that cycle. Generally, it has been noted that there is a degradation of rigidity with the rise in cyclic load.

Figure 10 demonstrates the dissimilarities of rigidity with cyclic load. During the initial cycle, the $3.65 \mathrm{kN} / \mathrm{mm}$ of rigidity was observed and there is a reduction in the rigidity when the load was raised to a peak of $32 \mathrm{kN}$. The $1.95 \mathrm{kN} / \mathrm{mm}$ of rigidity was attained during the last cyclic load.

When the frame is exposed to reverse cyclic loading, like those experienced during heavy wind or earthquake, a certain energy is absorbed in each cyclic load. It is equal to the work in straining or deforming the structure to the limit of deflection.

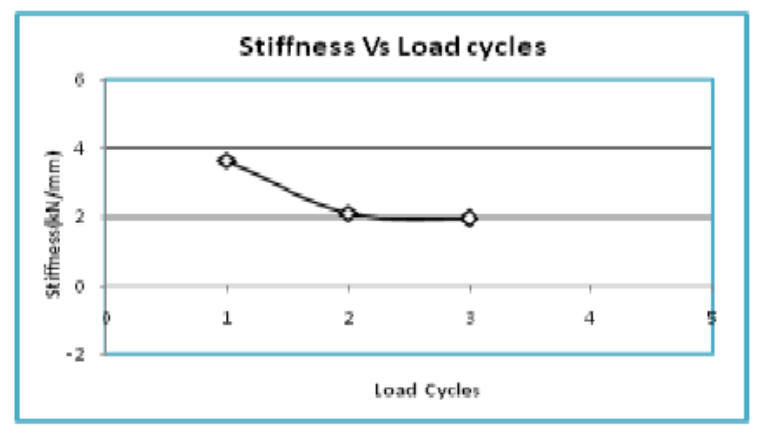

Figure 3. Dissimilarities of Rigidity with Cyclic load 


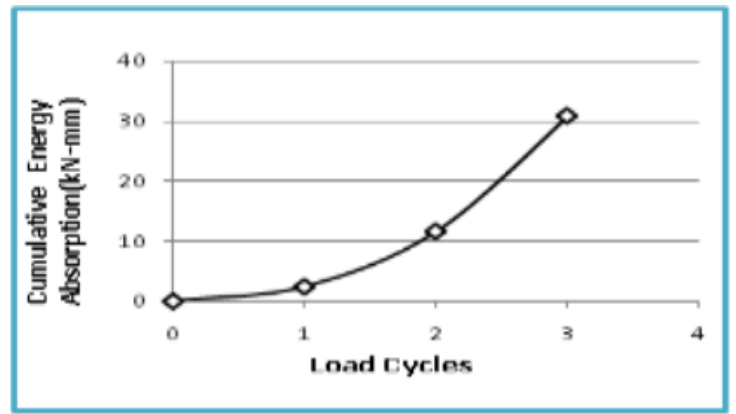

Figure 4. Cyclic load vs. Aggregate Energy absorbing

Figure 4 illustrates the aggregate energy-absorbing against cyclic load with single point load test for frame without NFRP mesh. During each cycle, the aggregate energy absorbency of the frame was achieved by addition of the energy absorbency of the frame. The values are measured and tabulated at each and every cycle as shown in Table 4 . When the $32 \mathrm{kN}$ of load was applied to frame without NFRP mesh, the aggregate energy-absorbing has been attained as $30.8 \mathrm{kN}-\mathrm{mm}$ at $32 \mathrm{kN}$ load.

Table 4.lists the results of the single point load test on the frame without NFRP mesh under back and forth load. The frame attains the 1.73 of peak ductility factor at $32 \mathrm{kN}$ load and also19.2kN-mm of peak energy absorbing. Similarly, the number of cycles rises in peak load convergences a peak deflection by Ductility factor, Aggregate Ductility factor, Energyabsorbing, Aggregate Energy absorbing and Rigidity.

\section{EXPERIMENTAL TEST RESULTS ON NFRP MESH CONCRETE FRAME WITH SINGLE POINT LOAD}

Figure 5. Demonstrates the dissimilarities of rigidity with cyclic load. The $4.0 \mathrm{kN} / \mathrm{mm}$ of the value of rigidity has been detected during the initial cycle and there is a reduce in the rigidity value for the increase in load until the $42 \mathrm{kN}$ of maximum during the final cycle of load with the $2.82 \mathrm{kN} / \mathrm{mm}$ of rigidity.

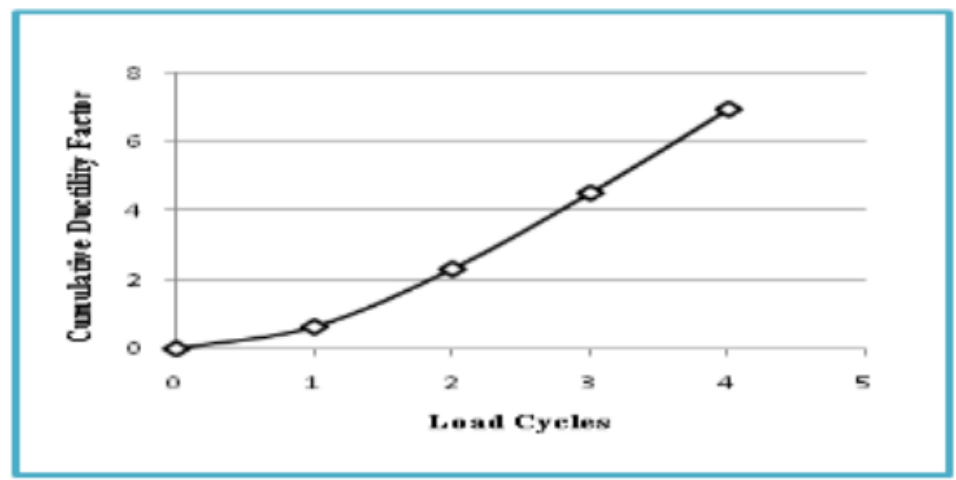

Figure 5. Cyclic load vs. Aggregate Ductility Factor

Figure 6.illustrates the aggregate energy-absorbing against cyclic load with a single point load test for frame with NFRP mesh. During every cycle, the energy absorbency of the frame was added to attain the aggregate energy absorbency of the frame and the values are tabulated at every cycle as shown in table 5 . The $40.2 \mathrm{kN}$-mm of aggregate energy-absorbing was observed by the frame with NFRP mesh at $42 \mathrm{kN}$ load. 


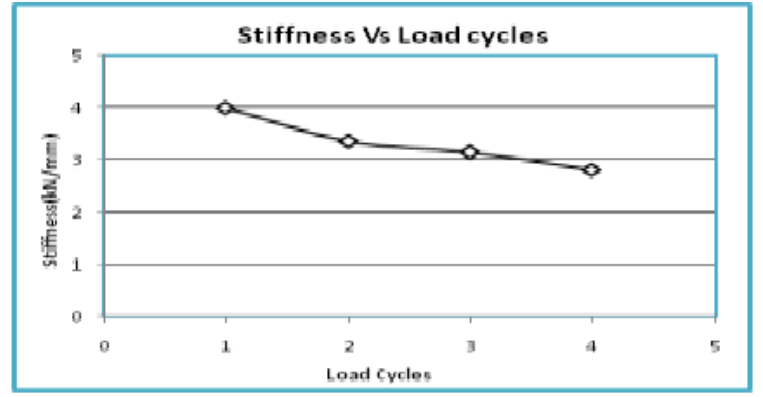

Figure 6. Dissimilarities of Rigidity with Cyclic load

Table 5 shows the results of the single point load test on the frame with NFRP mesh under back and forth load. The frame attains the 2.42 of peak ductility factor at $42 \mathrm{kN}$ load and also15.8kN-mm of peak energy absorbing. Likewise, the number of cycles enhances in peak load convergences a peak deflection by Ductility factor, Aggregate Ductility factor, Energy absorbing, Aggregate Energy absorbing and Rigidity.

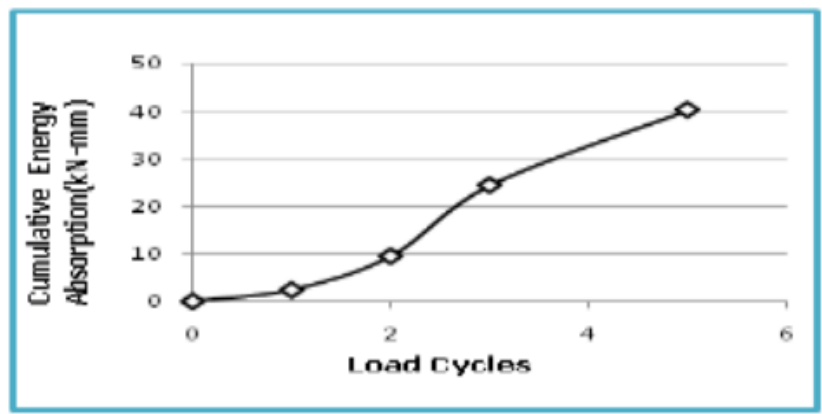

Figure 7. Cyclic load vs. Aggregate Energy absorbing

Table 5. Single Point Load test results on the frame (with NFRP mesh)

\begin{tabular}{|l|c|c|c|c|c|c|c|c|}
\hline S.No & $\begin{array}{c}\text { Cycle } \\
\text { No }\end{array}$ & $\begin{array}{c}\text { Peak } \\
\text { load } \\
\mathbf{( k N})\end{array}$ & $\begin{array}{c}\text { Peak } \\
\text { deflection } \\
(\mathbf{m m})\end{array}$ & $\begin{array}{c}\text { Ductility } \\
\text { factor }\end{array}$ & $\begin{array}{c}\text { Aggregate } \\
\mathbf{D . F}\end{array}$ & $\begin{array}{c}\text { Energy- } \\
\text { absorbing } \\
\mathbf{( k N}-\mathbf{m m})\end{array}$ & $\begin{array}{c}\text { Aggregate } \\
\text { Energy } \\
\text { absorbing } \\
(\mathbf{k N}-\mathbf{m m})\end{array}$ & $\begin{array}{c}\text { Rigidity } \\
\mathbf{( k N / m m})\end{array}$ \\
\hline \multicolumn{7}{|c|}{ Forward Cycle $(\Delta \mathrm{y}=1.45 \mathrm{~mm})$} \\
\hline 1 & 1 & 15 & 0.92 & 0.63 & 0.63 & 2.4 & 2.4 & 4 \\
\hline 2 & 2 & 27 & 2.42 & 1.67 & 2.30 & 7.1 & 9.5 & 3.37 \\
\hline 4 & 3 & 39 & 3.2 & 2.20 & 4.50 & 14.9 & 24.4 & 3.15 \\
\hline
\end{tabular}

\section{INITIAL FRACTURE LOAD AND ULTIMATE LOAD FOR FRAME WITH SINGLE POINT LOAD TEST}

Table 6 shows the initial fracture load and ultimate load for the frame with single point load test.

Table 6. Single Point load test results for Frame

\begin{tabular}{|c|c|c|c|}
\hline S. & Parameters & Traditional Concrete (kN) & NFRP Mesh Concrete (kN) \\
No & & 15 & 24 \\
\hline 1. & Initial fracture load & 32 & 42 \\
\hline 2. & Ultimate load & & \\
\hline
\end{tabular}




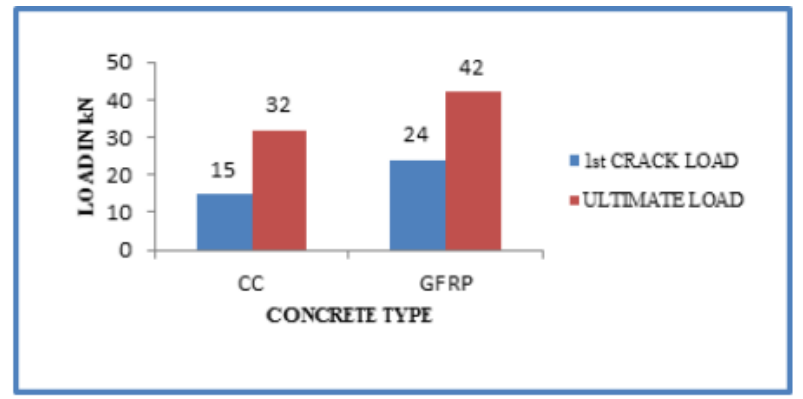

Figure 8. Comparison chart for a frame with Single Point load test results

Figure 8.illustrates the results of a single point load test for frame among the initial fracture load and ultimate load. As soon as the sample was positioned into the loading frame and the load application was commenced, the initial fracture was detected for traditional concrete at the load of $15 \mathrm{kNand}$ there is an increment in the load resistor at $24 \mathrm{kN}$ for NFRP mesh concrete. Also, a $32 \mathrm{kNof}$ ultimate load was detected for traditional concrete and $42 \mathrm{kN}$ was detected for NFRP mesh concrete. Thus, there is $24 \%$ increment in ultimate load for NFRP mesh concrete in comparison to the traditional concrete frame.

\section{CONCLUSION}

In this study, ANSYS 15 had been utilized to numerically examine the efficiency of beamcolumn joints and analysis of frames for samples of traditional and NFRP. According to static load condition these are examined experimentally. According to IS standard of M40 Grade of Concrete, the samples have been created. The Casted samples have been treated and tested by compression testing machine and loading frame machine. Several other tests were carried out for fresh concrete. In this study, it has been shown that the samples of NFRP perform important role in comparison to the samples of traditional.

Nano fiber mesh in the beam-column joint had been employed to predict different factors is causing the error of joints during various load conditions. Also, the various factors such as peak tension, peak deflection, ultimate load are used to study the external beam-column joints and the factor like rigidity are used for the conclusion.

- A sample of the frame with single PLT without NFRP mesh gives a $3.9 \mathrm{~mm}$ of peak deflection of at $32 \mathrm{kN}$ load whereas NFRP mesh gives a $3.52 \mathrm{~mm}$ of peak deflection at $42 \mathrm{kN}$ load. Thus, a sample of frame with single PLT improves the ultimate load to $23.8 \%$ and decreases the deflection of the sample to $9.74 \%$.

- The systematic and empirical results have been examined and discovered that situations provide the best output. Based on the results, the composites of Nano fiber mesh are adding at the joint together with the lateral reinforcement that does not allow the fractures at the edges of the joint interconnection between beam and column has been predicted.

- It was noted that the result from a mathematical study concurs well with the empirical study.

\section{REFERENCES}

[1] Pampanin, Stefano, Davide Bolognini, and Alberto Pavese. "Performance-based seismic retrofit strategy for existing reinforced concrete frame systems using fiber-reinforced polymer composites." Journal of Composites for Construction 11.2 (2007), pp 211-226.

[2] Rahman, Md Moshiur, et al. "Effect of adhesive replacement with cement mortar on NSM strengthened RC Beam." Revista de la Construcción. Journal of Construction 15.1 (2015), pp $61-72$. 
[3] Bindhu, K. R., and K. J. Sreekumar. "Seismic resistance of exterior beam column joint with diagonal collar stirrups." International Journal of Civil and Structural Engineering 2.1 (2011), pp 160.

[4] Sharma, Raju, and Prem Pal Bansal. "Behavior of RC exterior beam column joint retrofitted using UHP-HFRC." Construction and Building Materials 195 (2019), pp 376-389.

[5] Sandeep Panchal, Dr. Shashikant Sharma, Mohd. Mohsin Khan, Anurag Sharma and Dr. Amrit Kumar Roy, Effect of Glass Reinforcement and Glass Powder on the Characteristics of Concrete. International Journal of Civil Engineering and Technology, 8(3), 2017, pp. 637-647

[6] Jeon, Jong-Su, et al. "Fragility curves for non-ductile reinforced concrete frames that exhibit different component response mechanisms." Engineering Structures 85 (2015), pp 127-143.

[7] Genesio, Giovacchino. "Seismic assessment of RC exterior beam-column joints and retrofit with haunches using post-installed anchors." (2012).

[8] Abhishek Singh, B. R. Phanikumar and Ram Prasad. Effect of Geogrid Reinforcement on Load Carrying Capacity of A Coarse Sand Bed, International Journal of Civil Engineering and Technology, 7(3), 2016, pp. 01-06.

[9] Suresha P, Chikkanna N and Iranna M Biradar, Effect of Mechanical and Physical Properties of Aluminum Alloy LM12 with the Reinforcement of Silicon Carbide, International Journal of Production Technology and Management (IJPTM), 10(1), 2019, pp. 1-8.

[10] Dr. Ali H. Hallem, Talib A. Jasim and Dr. Nabaa S. Radhi, Effect of Alumina Reinforcement on Some Mechanical Properties of Aluminum Matrix Composites Produced by Stir Casting Process, International Journal of Civil Engineering and Technology (IJCIET) 9(10), 2018, pp. $1271-1280$

[11] Han, Ruilong, Yue Li, and John van de Lindt. "Assessment of seismic performance of buildings with incorporation of aftershocks." Journal of Performance of Constructed Facilities 29.3 (2014): 04014088.

[12] Sanad A.M and Hassan H.A, effect of corrosion on concrete reinforcement mechanical and physical properties, International Journal of Civil Engineering and Technology (IJCIET), Volume 4, Issue 3, May - June (2013), pp. 176-184

[13] Altin, Sinan, et al. "Improving shear capacity and ductility of shear-deficient RC beams using CFRP strips." Journal of Reinforced Plastics and Composites 29.19 (2010), pp 2975-2991.

[14] Tahnat, Yazan B. Abu, Mahmud MS Dwaikat, and Mohammad A. Samaaneh. "Effect of using CFRP wraps on the strength and ductility behaviors of exterior reinforced concrete joint." Composite Structures 201 (2018), pp 721-739.

[15] Shahbazpanahi, Shahriar. "The development of a dynamic fracture propagation model for FRP-strengthened beam-column joints." Journal of Vibro engineering 20.3 (2018), pp 13821391. 